\title{
Professional Values and Job Satisfaction Levels of Pediatric Nurses and Influencing Factors: A Cross- sectional Study
}

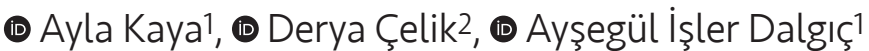 \\ ${ }^{1}$ Akdeniz University Faculty of Nursing, Department of Pediatric Nursing, Antalya, Turkey \\ ${ }^{2}$ Akdeniz University Hospital, Antalya, Turkey
}

\begin{abstract}
Aim: The aim of this cross-sectional study was to investigate the perceptions of professional values and job satisfaction levels of pediatric nurses and their influencing factors.

Materials and Methods: This study was conducted with 134 nurses working in the pediatric clinics of three hospitals in Turkey. Nurses' Professional Values scale and Minnesota Job Satisfaction Questionnaire were used to collect the data.

Results: It was found that the pediatric nurses had high professional values and that job satisfaction scores were moderate. It was further noted that pediatric nurses who were single, received their education in a nursing high school, had professional experience of 11-15 years in pediatric clinics, were working as clinical responsible nurse, and were working during the day shift regularly had higher scores of professional values. It was found that the job satisfaction of the pediatric nurses who were married, received their education in a nursing high school, had professional experience of 11-15 years in pediatric clinics, were working as clinical responsible nurse, and were working at day shift regularly, was significantly higher than the others. The results also indicated a positive and high correlation between pediatric nurses' perception of professional values and job satisfaction levels.

Conclusion: It was concluded that promoting professional values among nurses would eventually result in increasing levels of job satisfaction. We believe this study provides substantial data in this particular field in Turkey and it is hoped that it may be used to guide nursing managers to design well-established and unbiased programs for pediatric nurses.
\end{abstract}

Keywords: Pediatric nursing, professional values, job satisfaction, cross-sectional study

\section{Introduction}

Today, globalization, migration, nursing scarcity, new diseases, the aging population, and high quality care are complex issues that result in ethical problems for nurses $(1,2)$. For this reason, it is expected that nurses should be aware of professional values and use them in decision making processes while dealing with ethical problems $(2,3)$.
Professional values are standard guidelines, directions for professional actions, and clinical decision-making (4).

Contemporary nurses are expected to pay attention to professional values and reflect such values in their care practices (5-7). The results of several studies have shown that professional values enable nurses to assess care quality sensitively and enhance their care performances 
$(3,8-10)$. Therefore, it is extremely important to enhance professional values among nurses in order to improve and professionalize nursing practices (10). When nurses raise awareness of professional values, they can successfully transfer these values into their professional practices, which eventually results in enhanced patient care and increased job satisfaction (11-13).

Job satisfaction is characterized by the rapport between professional expectations and gains and this primarily signifies the professional attitudes, beliefs, knowledge, emotions, behaviors, and judgements of employees $(14,15)$. Job satisfaction is important in a nurse's work life (15). Nurses constitute the majority of human resources in medical care with 24-hour medical service. As nurses spend most of their days in their workplaces, job dissatisfaction will absolutely lead to life dissatisfaction in turn. In this case, physical, mental and social well-being might be impaired in the long-term. Consequently, nurses may experience job dissatisfaction and Burnout syndrome that manifests itself as distraction from their professional responsibilities, intentions to leave the profession, and high turnover rates $(12,16)$. It has been recently revealed that nurses with high levels of job satisfaction report more positive feelings and professional attitudes $(14,15,17)$.

Pediatric nurses support children by addressing important issues and dealing with their problems. In addition to meeting the child's needs, nurses communicate and collaborate with families and also fight with them. Pediatric nurses are responsible for enabling and facilitating ethical decision making in both children and their parents (9) as well as providing counseling and support to children and their parents to promote and maintain their health (1). Pediatric nursing is a special field of nursing that focuses on providing medical care particularly for children and their parents from infancy to late adolescence $(3,18,19)$. Especially pediatric nurses may be at higher risk due to the fact that children are usually seen as helpless and vulnerable (17). The major concerns that may affect job satisfaction in pediatric nurses are the difficult work conditions and the relatively more intensive care needed for pediatric patients (20). Therefore, pediatric nurses should raise awareness concerning professional values in order to ensure developed nursing practices, quality nursing care, professionalization, and enhanced job satisfaction. Studies to date have examined mainly nurses working with adult patients and their professional values and job satisfaction $(11,12,15)$.

It has been widely determined that the perception of professional values and job satisfaction play a great role in the professional careers of nurses. It has also been reported that developing professional values significantly improves the care satisfaction of patients and job satisfaction of nurses, enhances care quality and decreases the intent to leave the profession (11,12). Although recent studies have suggested a correlation among the concepts such as job satisfaction, professional values, and care quality, there is still a need for evidence-based studies to elaborate these correlations. This study also was conducted to pave the way for further studies by providing comprehensive data in this field. It is essential for nurses to integrate professional values into their professional practices in order to ensure professionalization and enhanced job satisfaction (11,12). However, professional values of pediatric nurses had not been thoroughly investigated to date. The aim of this study, therefore, was to provide data and pave the way for future studies and focus on perceptions of professional values and job satisfaction levels of pediatric nurses in particular and their influencing factors.

\section{Materials and Methods}

\section{Research Design}

This study was conducted with a cross-sectional design.

\section{Participants and Setting}

The study was conducted with 134 pediatric nurses working in three public hospitals in Turkey. All pediatric nurses (Total $=175$ ) in the city were included in the study. Therefore, no sampling method was used. Some nurses said that they were too busy and so did not want to participate in the study. The response rate was $93.7 \%$.

\section{Data Collection}

The data were collected between February 2016 and August 2016. Before the data collection, the participants were informed about the aim of the study. Given that their participation in the study would be voluntary, their written consents were obtained. The researchers distributed and collected the data forms on the same day. There was no time limitation for the participants to complete the forms.

\section{Data Collection Tools}

The personal information form, the Nursing Professional Values scale (NPVS), and the Minnesota Satisfaction Questionnaire (MSQ) were administered. The personal information form included questions about the descriptive characteristics of the participants such as age, gender, marital status, and their number of children as well as their educational status, current position at work, duration 
of service in the pediatric unit, and their shift work. The NPVS was used to analyze the professional values of the pediatric nurses. Developed by Weis and Schank (21), the NPVS is a five-point Likert scale with five subscales. In 2005, Orak adapted the scale into Turkish and conducted its reliability and validity testing (22). The scale has a total of 36 items and five subscales, namely dignity, responsibility, taking action, security and autonomy (22). The arithmetic mean was used to evaluate the total scores of the scale. An average score above 3.5 indicates high professional values. Higher scores signify that pediatric nurses place a great emphasis on professional values. The Cronbach's Alpha coefficient of the scale was found to be 0.95 (22). In the present study, the Cronbach's Alpha coefficient of the scale was found to be 0.92. The MSQ was used to assess job satisfaction levels of the pediatric nurses. Its original version with three subscales was developed by Weiss, Dawis and England (23). The reliability and validity study of the Turkish version of the questionnaire was conducted by Baycan (24). The Cronbach's alpha coefficient of the questionnaire was found to be 0.77 . The total score of the scale and subscales were evaluated using the arithmetic mean. An average score above 3.5 indicates high job satisfaction. Sabanciogulları and Dogan (15) reported that the Cronbach's Alpha coefficient of the questionnaire was 0.90 (15). In the present study, the Cronbach's alpha coefficient of the scale was 0.88 .

\section{Statistical Analysis}

The data were analyzed using the Statistical Program, version SPSS 23.0. The demographic characteristics of the pediatric nurses in the study were assessed. Professional values and job satisfaction scales were tested for reliability with Cronbach's Alpha coefficient. The data analysis was conducted with frequency, percentage distribution, arithmetic mean, analysis of variance, t-test, Tukey test, and Pearson correlation analysis. The analysis of the results was predicated on the basis of a significance level of 0.05 . Ethical principals were followed in the study.

\section{Ethical Considerations}

Ethical approval for this study was given by Akdeniz University Clinical Trials Ethics Committee (approval number: 70904504-23). The participants were informed about the study. Written permission from the hospitals and written consent from the participants were obtained.

\section{Results}

The results of the study revealed that the average age of the pediatric nurses was $32 \pm 0.77$ years $(\min =18 \max =51$ ), the average duration of working in the professional service was $15 \pm 1.44$ years $(\min =2, \max =32$ ), and the average duration of working as pediatric nurse was $7 \pm 1.36$ years ( $\mathrm{min}=1$, $\max =18$ ). It was also found that $97.8 \%$ of the participants were female and $45.5 \%$ were aged between $26-36$ years. While $73.1 \%$ of the participants were married, $38.1 \%$ had no child. It was also reported that $71.6 \%$ of the participants received education in a nursing high school. $87.3 \%$ of the participants were clinical nurses, $75.4 \%$ had been working as a pediatric nurse for 10 years or less, and 59\% were working in day and night shifts.

It was concluded that the professional values scores of the pediatric nurses were high; whereas, the job satisfaction scores were at moderate levels. Table 1 shows the NPVS and MSQ scores of the pediatric nurses. Table 2 shows the factors influencing the professional values and job satisfaction levels of the pediatric nurses.

The results also indicated a positive and high correlation between pediatric nurses' perception of professional values and their job satisfaction levels (Table 3).

\section{Discussion}

As a result of the study, it was found that the pediatric nurses perceived their professional values as high. This was satisfying in terms of reflecting the professionalism of the pediatric nurses. In a limited number of studies conducted with pediatric nurses, it was determined that the professional values scores of the nurses were high $(3,9,25)$. Professional values are important in the development of nursing care quality $(3,8-10)$. In addition, pediatric nurses

Table I. Mean Scores of Nursing Professional Values Scale and Minnesota Satisfaction Questionnare $(n=134)$

\begin{tabular}{|c|c|c|c|c|}
\hline Scales & Mean & SD & Min & Max \\
\hline \multicolumn{5}{|l|}{ NPVS } \\
\hline Total score & 3.87 & 0.58 & 2.47 & 5.00 \\
\hline Dignity & 3.99 & 0.64 & 2.27 & 5.00 \\
\hline Responsibility & 3.89 & 0.89 & 2.44 & 5.00 \\
\hline Taking action & 3.94 & 0.94 & 2.38 & 5.00 \\
\hline Security & 4.10 & 0.64 & 2.50 & 5.00 \\
\hline Autonomy & 4.08 & 0.75 & 1.75 & 5.00 \\
\hline \multicolumn{5}{|l|}{ MSQ } \\
\hline Overall satisfaction & 3.40 & 0.71 & 1.60 & 5.00 \\
\hline Internal satisfaction & 3.53 & 0.53 & 1.58 & 5.00 \\
\hline External satisfaction & 3.20 & 0.78 & 1.38 & 5.00 \\
\hline
\end{tabular}


are responsible for supporting the families of the patients in many cases $(1,9)$. Pediatric nurses can provide effective care by being aware of the needs of the children and their families as well as the means of optimum healthcare services and opportunities of families under all circumstances.

Table II. Factors influencing the professional values and job satisfaction levels of pediatric nurses $(n=134)$

\begin{tabular}{|c|c|c|c|c|}
\hline $\begin{array}{l}\text { Descriptive } \\
\text { characteristics }\end{array}$ & $\mathbf{n}$ & $\%$ & $\begin{array}{l}\text { NPVS } \\
X \pm S D\end{array}$ & $\begin{array}{l}M S Q \\
X \pm S D\end{array}$ \\
\hline \multicolumn{5}{|l|}{ Marital status } \\
\hline Married & 98 & 73.1 & $3.65 \pm 0.51$ & $3.69 \pm 0.39$ \\
\hline \multirow[t]{2}{*}{ Single } & 36 & 26.9 & $3.91 \pm 0.58$ & $3.33 \pm 0.69$ \\
\hline & & & $p=0.01$ & $p=0.04$ \\
\hline \multicolumn{5}{|l|}{ Educational level } \\
\hline $\begin{array}{l}\text { Vocational high } \\
\text { school of nursing }\end{array}$ & 12 & 9.0 & $3.75 \pm 0.54$ & $3.39 \pm 0.71$ \\
\hline Vocational college & 14 & 10.4 & $3.78 \pm 0.70$ & $3.25 \pm 0.79$ \\
\hline BSN & 96 & 71.6 & $4.20 \pm 0.16$ & $3.54 \pm 0.68$ \\
\hline \multirow[t]{2}{*}{ MSN } & 12 & 9.0 & $3.87 \pm 0.57$ & $3.14 \pm 0.93$ \\
\hline & & & $p=0.01$ & $p=0.02$ \\
\hline \multicolumn{5}{|c|}{ Total service as pediatric nurse (years) } \\
\hline$\leq 10$ & 81 & 60.4 & $3.71 \pm 0.57$ & $3.34 \pm 0.73$ \\
\hline $11-15$ & 36 & 26.9 & $4.06 \pm 0.64$ & $3.59 \pm 0.79$ \\
\hline \multirow[t]{2}{*}{$\geq 16$} & 17 & 12.7 & $3.56 \pm 0.63$ & $3.50 \pm 3.64$ \\
\hline & & & $p=0.01$ & $p=0.03$ \\
\hline \multicolumn{5}{|l|}{ Position at work } \\
\hline Clinical nurse & 117 & 87.3 & $3.86 \pm 0.60$ & $3.54 \pm 0.72$ \\
\hline \multirow[t]{2}{*}{ Chief nurse } & 17 & 12.7 & $4.08 \pm 0.29$ & $3.39 \pm 0.72$ \\
\hline & & & $p=0.02$ & $p=0.04$ \\
\hline \multicolumn{5}{|l|}{ Work type } \\
\hline Daytime & 48 & 35.8 & $3.98 \pm 0.58$ & $3.62 \pm 0.64$ \\
\hline Night & 7 & 5.2 & $3.77 \pm 0.41$ & $3.50 \pm 0.62$ \\
\hline \multirow[t]{2}{*}{ Shift } & 79 & 59.0 & $3.72 \pm 0.60$ & $3.31 \pm 0.75$ \\
\hline & & & $p=0.01$ & $p=0.04$ \\
\hline
\end{tabular}

Table III. Nursing Professional Values Scale, Minnesota Satisfaction Questionnaire $(n=134)$

\begin{tabular}{|l|l|l|}
\hline \multicolumn{2}{|c|}{} & NPVS \\
\hline \multirow{2}{*}{ MSQ } & $\mathbf{r}$ & 0.831 \\
\cline { 2 - 3 } & $\mathbf{P}$ & 0.01 \\
\hline \multicolumn{2}{|l|}{$\begin{array}{l}\text { P<0.05, NPVS: Nursing Professional Values scale, MSQ: Minnesota satisfaction } \\
\text { questionnaire }\end{array}$} \\
\hline
\end{tabular}

Children are different from adults in terms of biological, psychological, and social aspects and they are also more vulnerable than adults in terms of exposure to violations of rights. Ethical issues caused by all of these main differences in pediatric nursing have brought new discussions into the open (26). At this point, it is important for pediatric nurses to perceive professional values as high in order to make correct decisions. Therefore, it is thought that pediatric nurses perceive professional values as high, reflect them in practices and implement them in order to protect and promote the child's health. In the present study, the job satisfaction level of the pediatric nurses was found to be moderate. According to studies in different countries, job satisfaction levels of nurses are moderate $(12,13,20,27)$. In a limited number of studies conducted with pediatric nurses, it was determined that their job satisfaction scores were moderate $(14,17,28)$. Our results are compatible with the literature.

The pediatric nurses who were single, had a bachelor's degree, had been working in child nursing for 11-15 years, were in the position of clinical nurse specialist and working on the daytime shift had higher professional value scores. There are different statuses for nursing education in Turkey. Pediatric nurses with 4 years of university education may be considered to have higher professional values than others. In the study conducted by Yazıcıoğlu Sorucuoğlu and Güdücü Tüfekci (3) with 224 pediatric nurses, they stated that the professional values of those nurses who were single and nursing nurses were significantly higher (3). In another study conducted with pediatric nurses, professional value scores of post-graduate and day shift nurses were found to be high (25). The results of the present study are partially consistent with the literature. Those pediatric nurses who were married, had a bachelor's degree, had been working in child nursing for 11-15 years, in the position of clinical nurse specialist and working on the daytime shift had higher a job satisfaction level. In studies on the job satisfaction levels of pediatric nurses (14), job satisfaction levels of nurses who were working continuously in daytime work and were graduates (27) were higher than others.

The fact that nurses strive to provide quality care to patients, look out for them, advocate for them, and support them to make conscious decisions can be achieved only with an adoption of professional values and high job satisfaction $(13,29)$. The results of this study also suggested a positive and moderately significant correlation between the perception of professional values and job satisfaction. In the study conducted by Yarbrough et al. (11), they found that attempts to improve the professional values of nurses 
resulted in enhanced job satisfaction. Similarly, it was reported that there was a positive significant correlation between professional values and job satisfaction in nurses (12). This result was compatible with the results of previous studies. It can be reasonably suggested that raising awareness concerning professional values will improve the job satisfaction of nurses.

\section{Study Limitations}

The present study has several limitations. One of the limitations is that the data were obtained only from three public hospitals in Antalya, Turkey. Future studies with larger sample groups are needed in Turkey. Another limitation of this study is that the majority of the participants were female. For this reason, the results of this study cannot be generalized to mixed gender groups.

\section{Conclusion}

The mean scores of the professional values of the pediatric nurses were high and their job satisfaction scores were moderate. Marital status, education level, working duration in pediatric nursing, working position, and shift were related to the professional values of pediatric nurses and their job satisfaction. It was found that there was a positive and moderate correlation between the perception of professional values and job satisfaction in pediatric nurses.

In the light of the results of this study, it is recommended that the professional values and job satisfaction of pediatric nurses are improved. Additionally, it is considered to be crucial to implement new strategies to maintain professional values in order to increase job satisfaction levels. Nevertheless, there is still an urgent need to conduct further studies investigating the professional values of pediatric nurses. It is also suggested that the factors that influence the professional values of pediatric nurses are analyzed, and thus the professional values of pediatric nurses are improved. Further studies are needed to validate the results of this study and to evaluate the possible impacts of interventions to enhance professional values and job satisfaction. It is recommended that educational and promotional programs are designed to enhance the pediatric nurses' perceptions concerning professional values.

The results of this study will be valuable for nursing managers of pediatric units to understand current levels of professional values and job satisfaction. These have significant implications for policy makers in re-examining aspects of management and nursing practice. These findings can guide pediatric nursing managers to highlight the importance of awareness on professional values among pediatric nurses as caregivers with high job satisfaction. Nursing managers play an important role in the formation of safe working environments and the enhancement of job satisfaction due to their tasks and responsibilities as well as their authorizations. This study, therefore, is thought to provide substantial data in this field in Turkey and to guide the Ministry of Health, nursing managers, hospital management, and non-governmental organizations to design well-established and unbiased programs for pediatric nurses. Finally, it is recommended that similar studies with pediatric nurses in different medical settings are conducted so that nursing managers can evaluate the validity of the test results.

\section{Acknowledgments}

The authors would like to thank all participants in this study.

\section{Ethics}

Ethics Committee Approval: Ethical approval for this study was given by Akdeniz University Clinical Trials Ethics Committee (approval number: 70904504-23).

Informed Consent: Written permission from the hospitals and written consent from the participants were obtained.

Peer-review: Externally peer-reviewed.

\section{Authorship Contributions}

Concept: A.K., D.Ç., A.I.D., Design: A.K., D.Ç., Data Collection or Processing: A.K., D.Ç., Analysis or Interpretation: A.K., A.I.D., Literature Search: A.K., D.Ç., Writing: A.K., D.Ç., A.I.D.

Conflict of Interest: No conflict of interest was declared by the authors.

Financial Disclosure: The authors declared that this study received no financial support.

\section{References}

1. Esenay Fl, Yigit R, Binay S, Erdoğan S. Occupational satisfaction and implementation of roles and functions: a national survey of pediatric nurses in Turkey. Intern Ref J Gynaecol Dis Matern Child Health 2017;10:1-17.

2. Poorchangizi B, Farokhzadian J, Abbaszadeh A, Mirzaee $M$ Borhani F. The importance of professional values from clinical nurses' perspective in hospitals of a medical university in Iran. BMC Med Ethics 2017;18:20.

3. Yazıcı-Sorucuoğlu A. Güdücü-Tüfekçi $F$. Çocuk hemşirelerinde mesleki profesyonel değerler. ACU Sağlık Bil Derg 2015;6:105-9.

4. Parandeh A, Khaghanizade M, Mohammadi E, Mokhtari Nouri J. Factors influencing development of professional values among 
nursing students and instructors: a systematic review. Glob J Health Sci 2014;7:284-93.

5. Kaya A, Boz i. The development of the Professional Values Model in Nursing. Nurs Ethics 2019;26:914-23.

6. Riklikiene $\mathrm{O}$, Karosas L, Kaseliene S. General and professional values of student nurses and nurse educators. I Adv Nurs 2018;74:666-76.

7. Al Shammari F, Grande RAN. Vicencio DA. Al Mutairi S. Nurses' professional values on patient care provisions and decisions. I Nurs Educ Pract 2017;7:78-84.

8. Lyneham J, Levett-Jones T. Insights into registered nurses' professional values through the eyes of graduating students. Nurs Educ Pract 2016;17:86-90.

9. Gallegos C. Sortedahl C. An exploration of professional values held by nurses at a large freestanding pediatric hospital. Pediatr Nurs 2015;41:187-95.

10. Moon S, Kim DH, Kim EJ, Kim YJ, Lee S. Evaluation of the validity and reliability of the Korean version of the Nursing Professional Values Scale-Revised. Nurs Educ Today 2014;34:325-30.

11. Yarbrough S, Martin P, Alfred D, McNeill, C. Professional values, job satisfaction, career development, and intent to stay. Nursing Ethics 2017;24:675-85

12. Kantek F, Kaya A. Professional values, job satisfaction, and intent to leave among nursing managers. J Nurs Res 2017;25:31925.

13. Ravari A, Bazargan-Hejazi S, Ebadi A, Mirzaei T, Oshvandi K. Work values and job satisfaction: A qualitative study of Iranian nurses. Nurs Ethics 2013;20:448-58.

14. Akman O, Ozturk C, Bektas M, Ayar D, Armstrong MA. Job satisfaction and burnout among paediatric nurses. I Nurs Manage 2016;24:923-33.

15. Sabanciogullari S, Dogan S. Relationship between job satisfaction, professional identity and intention to leave the profession among nurses in Turkey. I Nurs Manage 2015;23:107685.

16. Barutcu E, Serinkan C. Burnout syndrome: an important problem today and a research study conducted in Denizli. Ege Academic Review 2008;8:541-61.

17. Meyer RM, Li A, Klaristenfeld J, Gold JI. Pediatric novice nurses: examining compassion fatigue as a mediator between stress exposure and compassion satisfaction, burnout, and job satisfaction. I Pediatr Nurs 2015;30:174-83.

18. Enskär K, Huus K, Björk M, Granlund M, Darcy L, Knutsson S. An analytic review of clinical implications from nursing and psychosocial research within Swedish pediatric oncology. I Pediatr Nurs 2015;30:550-9.

19. Teksöz E, Ocakcı AF. Çocuk hemşireliğinde sanat uygulamaları. Dokuz Eylül Üniversitesi Hemşirelik Yüksekokulu Dergisi 2014;7:119-23.

20. Sekol MA, Kim SC. Job satisfaction, burnout, and stress among pediatric nurses in various specialty units at an acute care hospital. J Nurs Educ and Pract 2014;4:115-24.

21. Weis $D$, Schank, MJ. An instrument to measure professional nursing values. I Nurs Sch 2000;32:201-4.

22. Orak SN. Analysis of factors affecting and professional nursing value of nurses in the province of Istanbul (Doctoral dissertation). Istanbul, Turkey: Marmara University/Institute of Health Sciences 2005.

23. Weiss DI, Dawis RV, England GW. Manual for the Minnesota Satisfaction Questionnaire. Minnesota Studies in Vocational Rehabilitation 22, Minneapolis, MN: University of Minnesota 1967.

24. Baycan AF. Analysis of Several Affects of Job Satisfaction Between Different Occupational Groups (Master's dissertation). Istanbul, Turkey: Bogazici University/Institute of Health Science 1985.

25. Zengin M, Yayan EH, Yıldırım N, Akın E, Avşar Ö, Mamiş E. Pediatri hemşirelerinin profesyonel değerlerinin profesyonel tutumlarına etkisi. Sağlık Bilimleri ve Meslekleri Dergisi 2018;5:316-23.

26. Tazegün A, Çelebioğlu A. Ethical sensitivity levels of pediatric nurses and the factors affecting this sensitivity. İzmir Dr. Behçet Uz Çocuk Hast. Dergisi 2016;6:97-102.

27. Aytekin A. Yılmaz Kurt F. Yenidoğan Yoğun Bakım Kliniği'nde çalışan hemşirelerde iş doyumu ve etkileyen faktörler. İzmir Dr. Behçet Uz Çocuk Hast Dergisi 2014;4:51-8.

28. Adwan IZ. Pediatric nurses' grief experience, burnout and job satisfaction. J Pediatr Nurs 2014;29:329-36

29. Gurkova E, Cap I, Ziakova K, Duriskova M. Job satisfaction and emotional subjective well-being among Slovak nurses. Int Nurs Rev 2012;59:94-100. 